\title{
KESETIMBANGAN PROSES DESORPSI AMONIA DARI ARANG AKTIF HASIL PIROLISIS LIMBAH BIOMASSA
}

\author{
Hasni $^{{ }^{*}}$, Syamsuddin Yani ${ }^{1}$, Andi Aladin ${ }^{1}$, dan Mimin Septiani ${ }^{2 *}$ \\ ${ }^{1}$ Program Magister Teknik Kimia, Pascasarjana Universitas Muslim Indonesia \\ Jl. Urip Sumiharjo No.225 Makassar, 90232 \\ ${ }^{2}$ Jurusan Teknik Kimia, Sekolah Tinggi Teknologi Industri Bontang, Kalimantan Timur \\ *)Email: hasni77.hn@gmail.com ; mhimns@gmail.com
}

\begin{abstract}
Ammonia which is bound to the adsorbent can interfere adsorption process, so that release the compound can be done by desorption process. This research intends to know appropriate equilibrium models to determine maximum capacity of active carbon for desorption ammonia. The method which used in desorption process are Langmuir and Freundlich isotherm models. The research was performed with variation of active carbon mass and variation of contact time. The concentration of ammonia on the desorption process was determined using spectrophotometer at $\lambda 420 \mathrm{~nm}$. The experiment result showed that the more the active carbon dosage is used, the more the concentration of ammonia is increased. Optimum contact time during 7 hours with desorption percentage $94-96 \%$. This research of ammonia desorption by active carbon followed the Langmuir equilibrium model $\mathrm{R}^{2} 0.954$ and Freundlich equilibrium model $\mathrm{R}^{2}$ 0.952. The equilibrium equation is used Langmuir equation $y=-0.015 x+3.185$, maximum desorption capacity is $66.67 \mathrm{mg} / \mathrm{g}$.
\end{abstract}

Keywords: Active carbon, Adsorption, Ammonia, Desorption, Equilibrium

\section{PENDAHULUAN}

Arang aktif adalah salah satu jenis adsorben yang digunakan dan banyak dikembangkan untuk adsorpsi dikarenakan memiliki kapasitas adsorpsi yang besar dan dapat diregenerasi ulang (Zawani et al., 2009). Arang aktif dapat dibuat dari berbagai bahan organik yang memiliki kandungan karbon tinggi, seperti tempurung kelapa, kayu, tulang, gambut, dan batubara (smisek \& Cerny 1970). Secara umum masyarakat menggunakan arang aktif dalam proses adsorpsi untuk menyerap zat-zat pengotor di dalam air (Setyoningrum, et al., 2018).. Namun pada prosesnya terdapat amonia yang terikat pada gugus-gugus arang aktif yang dapat mengganggu proses adsorpsi. Hal ini berdampak terhadap adanya kontaminasi larutan yang diadsorpsi. Proses pelepasan amonia dapat dilakukan dengan cara desorpsi. Desorpsi adalah pelepasan kembali ion/molekul yang telah berikatan dengan gugus aktif pada adsorben (Wankasi, 2005). Untuk mengetahui performa dari arang aktif yang digunakan, perlu dilakukan studi kesetimbangan dari proses yang berlangsung. Model kesetimbangan yang banyak dikenal untuk memahami sistem adsorpsi adalah persamaan isoterm Langmuir dan Freundlich.

Penelitian yang telah dilakukan Allwar dkk (2015) menunjukkan bahwa arang aktif dari cangkang kelapa sawit sangat baik dijadikan adsorben dalam penghilangan fenol dan 2-klorofenol yang terkandung di dalam air. Studi kesetimbangan menunjukkan adsorpsi fenol memenuhi model isoterm Langmuir dan Freundlich, sedangkan adsorpsi 2-klorofenol memenuhi model isoterm Freundlich.

Adsorpsi amonia telah banyak dilakukan dengan menggunakan berbagai adsorben. Boopathy, dkk (2012) telah melakukan kajian mengenai studi kinetika, isoterm dan termodinamika pada proses adsorpsi ion ammonium oleh arang aktif tempurung kelapa. Penghilangan amonia dapat menggunakan zeolit tipe 13X (Zheng et al., 2008), Amonia juga dapat diturunkan dengan arang aktif dari ampas kopi 
(Irmanto dan Suyata, 2009), serta dengan fly ash (Murti et al., 2013)

Desorpsi kadmium(II) yang terikat pada biomassa menunjukkan bahwa konsentrasi larutan dan waktu kontak mempengaruhi proses desorpsi (Adha et al., 2015). Waktu kontak memberikan perubahan secara signifikan terhadap proses penyerapan pada kondisi optimum (Syafrianda et al., 2017).

Penelitian ini bertujuan untuk mengetahui model kesetimbangan yang sesuai pada peristiwa desorpsi amonia pada arang aktif cangkang kelapa sawit, sehingga dapat ditentukan kapasitas desorpsi dari arang aktif tersebut.

\section{METODE PENELITIAN}

\section{Waktu dan Tempat}

Penelitian ini dilakukan di Laboratorium SMTI Makassar, dari bulan September-Desember, 2018.

\section{Alat Penelitian}

Peralatan yang digunakan dalam penelitian ini adalah cawan porselin, labu takar, geles beker, pipet ukur, wadah sampel, kuvet, botol semprot, timbangan, batang pengaduk, kertas saring dan spektrofotometer uv-vis.

\section{Bahan Penelitian}

Bahan-bahan yang digunakan pada penelitian ini yaitu arang aktif yang berasal dari cangkang sawit PT. So Good Food (Maros), $\mathrm{NH} 4 \mathrm{Cl}$, pereaksi nessler, sampel air, aquadest.

\section{Prosedur Penelitian}

Tahap 1. Persiapan

Pembuatan larutan standar amonia dengan konsentrasi 0.5, 1, 2, 4, 6 ppm. Penghalusan dan pengayakan arang cangkang aktif yang telah diaktivasi. Pengukuran konsentrasi awal larutan sampel.

Tahap 2. Analisa pengaruh dosis arang aktif dan penentuan waktu kesetimbangan.

Disiapkan beberapa wadah sampel dan dimasukkan masing-masing 1 L larutan sampel yang konsentrasinya telah diukur. Kedalam masingmasing larutan dimasukkan arang aktif dengan variasi massa $0.0 ; 3 ; 5 ; 8 ; 13$ gram. Larutan diaduk dengan batang pengaduk, dilakukan variasi waktu 0 ; $0.5 ; 2 ; 4 ; 7 ; 12 ; 18$ jam pada suhu ruang. Campuran kemudian disaring dan filtratnya dicampurkan dengan $1 \mathrm{ml}$ pereaksi nessler kemudian dibiarkan bereaksi selama 1 jam. Setelah bereaksi diuji dengan spektrofotometer dengan panjang gelombang 420 $\mathrm{nm}$.

\section{HASIL DAN PEMBAHASAN}

\section{Pengaruh Dosis Arang Aktif}

Penentuan pengaruh dosis arang aktif terhadap desorpsi amonia dilakukan dengan variasi massa arang aktif $3 ; 5 ; 8 ; 13$ gr. Arang aktif direndam di dalam larutan kemudian konsentrasi amonia pada larutan dianalisa sehingga didapatkan perubahan konsentrasi berdasarkan masing-masing dosis arang aktif yang digunakan.

Gambar 1 menunjukkan pengaruh penambahan dosis arang aktif terhadap konsenstrasi amonia yang dihasilkan pada larutan.

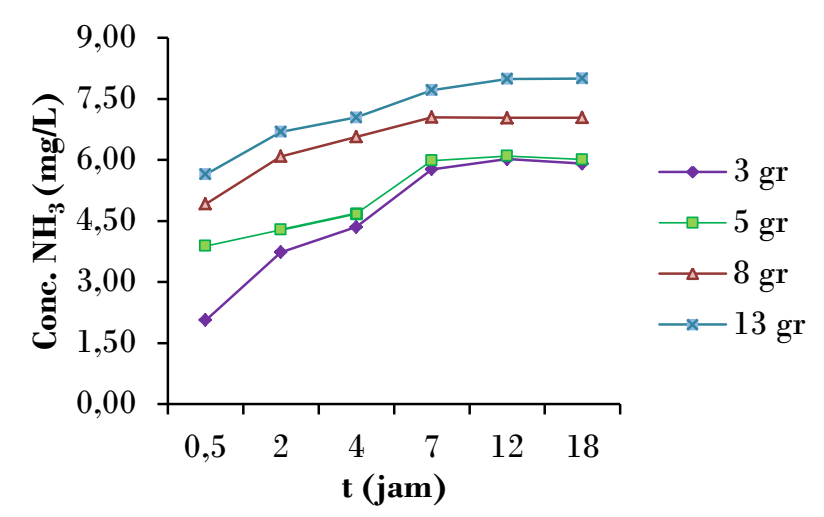

Gambar 1. Grafik pengaruh waktu kontak dan dosis arang aktif terhadap peningkatan konsentrasi amonia dalam larutan

Hasil analisis menunjukkan bahwa semakin meningkat dosis arang aktif yang digunakan, maka semakin meningkat pula konsentrasi amonia dalam larutan. Hal ini dikarenakan makin besarnya ratio massa arang aktif terhadap larutan maka makin besar pula luas bidang kontaknya (Mulyono dan Wibisono, 2007).

Hal tersebut menunjukkan bahwa penambahan dosis arang aktif berpengaruh terhadap peningkatan konsentrasi amonia pada proses desorpsi dari arang aktif cangkang sawit. Namun, pada kondisi tertentu juga tampak bahwa penambahan dosis arang aktif tidak meningkatkan konsentrasi amonia dalam larutan atau dengan kata lain kadar amonia yang terdesorpsi dari arang aktif relatif sangat kecil. 
Pada kondisi penambahan dosis terbesar (13 g) konsentrasi amonia dalam larutan masih terus mengalami peningkatan, namun perbedaan peningkatan konsentrasi amonia yang terjadi tidak terlalu signifikan, hal ini terjadi karena gaya tarik menarik antara ion amomonia pada karbon aktif dan larutan tidak begitu kuat akibat luas permukaan yang tersedia terlalu besar (Mulyono dan Wibisono, 2007). Konsentrasi amonia pada arang aktif tidak mampu diakomodasi oleh seluruh permukaan larutan yang tersedia. Sehingga jika dosis arang aktif terus dinaikkan maka kemungkinan akan tercapai titik jenuh antara konsentrasi larutan dan arang aktif.

\section{Penentuan Waktu Kesetimbangan}

Analisis penentuan waktu kesetimbangan ini bertujuan untuk mendapatkan waktu kesetimbangan desorpsi amonia dari karbon aktif cangkang kelapa sawit. Waktu kesetimbangan merupakan waktu dimana persentase desorpsi terhadap amonia tidak berubah atau sudah konstan. Hal ini ditunjukkan dengan tidak terjadinya lagi perubahan konsentrasi dalam larutan.

Gambar 2. menunjukkan bahwa persentase desorpsi mengalami peningkatan seiring dengan lamanya waktu kontak yang terjadi, peningkatan ini terjadi sebelum kesetimbangan tercapai. Pada waktu kontak setelah 7 jam, terlihat bahwa persentase amonia yang terdesorpsi mengalami perubahan yang relatif sangat kecil atau konstan, hal ini menunjukkan bahwa pada kondisi ini kesetimbangan telah tercapai.

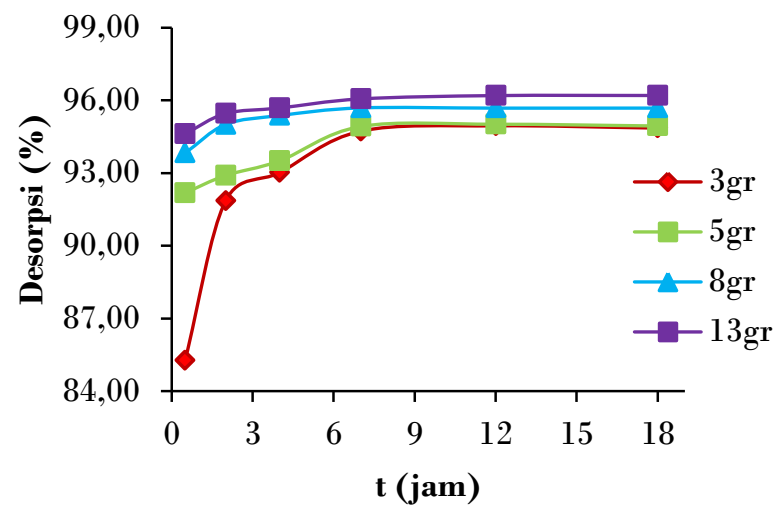

Gambar 2. Grafik pengaruh waktu kontak terhadap persentase desorpsi amonia

Disisi lain proses desorpsi terjadi sangat cepat pada awal waktu kontak. Interaksi elektrostatik antara ion amonia dan permukaan larutan yang terjadi merupakan salah satu kemungkinan terjadinya desorpsi secara cepat di awal waktu kontak (Adha dkk, 2015).

\section{Penentukan model kesetimbangan}

Penentuan model kesetimbangan desorpsi ion amonia oleh arang aktif ditentukan dengan metode regresi linier dan dari persamaan regresi akan diperoleh nilai $\mathrm{R}^{2}$ (Aditya et al, 2016). Penentuan model kesetimbangan dilakukan dengan cara mengolah data yang diperoleh menurut ketentuan persamaan Freundlich dan Langmuir.

Persamaan Isoterm Freundlich:

$$
\mathrm{q}_{\mathrm{e}}=\mathrm{K}_{\mathrm{f}} \mathrm{C}_{\mathrm{e}}^{\frac{1}{\mathrm{n}}}
$$

Bentuk Logaritmik persamaan Freundlich menurut Panneerselvam et al., (2009) dapat ditulis menjadi (Freundlich, 1906):

$$
\log \mathrm{q}_{\mathrm{e}}=\mathrm{K}_{\mathrm{f}}+\frac{1}{\mathrm{n}} \log \mathrm{C}_{\mathrm{e}}
$$

Menurut Panneerselvam, et al. (2009) persamaan isoterm Langmuir dapat ditulis sebagai berikut (Langmuir, 1918):

$$
\mathrm{q}_{\mathrm{e}}=\frac{\mathrm{bQ}_{0} \mathrm{C}_{\mathrm{e}}}{1+\mathrm{bC}_{\mathrm{e}}} .
$$

bentuk liniearisasi menjadi:

$$
\frac{\mathrm{C}_{\mathrm{e}}}{\mathrm{q}_{\mathrm{e}}}=\frac{1}{\mathrm{Q}_{0} \mathrm{~b}}+\frac{\mathrm{C}_{\mathrm{e}}}{\mathrm{Q}_{0}}
$$

dengan qe adalah jumlah adsorbat terserap per massa padatan pada kesetimbangan $(\mathrm{mg} / \mathrm{g})$, Ce adalah konsentrasi larutan pada kesetimbangan (mg/L), Kf adalah kapasitas adsorpsi relative adsorben $(\mathrm{mg} / \mathrm{g}), \frac{1}{\mathrm{n}}$ adalah konstanta yang berhubungan dengan energi adsorpsi (mg/g) dan b adalah konstanta yang berhubungan dengan energi adsorpsi.

Hasil pengaluran linear log qe terhadap $\log \mathrm{Ce}$ (model freundlich) dan 1/qe terhadap Ce/qe (model Langmuir) akan diperoleh nilai koefisien relasi $\mathrm{R}^{2}$ yang menunjukkan kecenderungan pemilihan model isoterm yang sesuai untuk adsorpsi yang terjadi.

Konsentrasi ion amonia yang terserap oleh adsorben juga dapat ditentukan dengan rumus (Estiaty, 2013):

$$
\mathrm{qe}=(\mathrm{Co}-\mathrm{Ce}) \times \mathrm{V} / \mathrm{m} \text {. }
$$

Keterangan:.

$\mathrm{qe}=$ Jumlah adsorbat terserap per massa padatan pada kesetimbangan, $\mathrm{mg} / \mathrm{g}$

$\mathrm{Co}=$ Konsentrasi awal larutan, $\mathrm{mg} / \mathrm{L}$ 
$\mathrm{Ce}=$ Konsentrasi larutan pada

kesetimbangan, $\mathrm{mg} / \mathrm{L}$

$\mathrm{m}=$ Massa adsorben, $\mathrm{g}$

$\mathrm{v}=$ Volume larutan pada percobaan, $\mathrm{L}$

Tabel 1 menunjukkan hasil pengaluran linear $\log$ qe terhadap $\log \mathrm{Ce}$ (Freundlich) dan Ce/qe terhadap Ce (Langmuir) dan persamaan serta nilai korelasi $\left(\mathrm{R}^{2}\right)$ dari kedua persamaan tersebut ditunjukkan pada Tabel 1.

Tabel 1. Hasil pengaluran linear terhadap persamaan isoterm Freundlich dan Langmuir

\begin{tabular}{ccccc}
\hline \multirow{2}{*}{$\begin{array}{c}\text { Waktu } \\
\text { Kontak } \\
(\text { Jam })\end{array}$} & $\begin{array}{c}\text { Persamaan } \\
\text { Linear }\end{array}$ & $R^{2}$ & \multicolumn{2}{c}{ Persamaan } \\
Linear & $R^{2}$ \\
\hline \multirow{2}{*}{0.5} & $\mathrm{y}=0.155 \mathrm{x}$ & 0.882 & $\mathrm{y}=-0.11 \mathrm{x}+$ & \\
& -0.318 & 0.580 & 0.795 \\
& & 3.560 & \\
2 & $\mathrm{y}=0.097 \mathrm{x}$ & 0.950 & $\mathrm{y}=-0.044 \mathrm{x}$ & 0.947 \\
& -0.044 & & +3.309 & \\
4 & $\mathrm{y}=0.082 \mathrm{x}$ & & $\mathrm{y}=-0.033 \mathrm{x}$ & \\
& -0.036 & 0.917 & +3.261 & 0.917 \\
7 & $\mathrm{y}=0.047 \mathrm{x}$ & 0.952 & $\mathrm{y}=-0.015 \mathrm{x}$ & 0.954 \\
& -0.202 & & +3.185 & \\
12 & $\mathrm{y}=0.045 \mathrm{x}$ & 0.919 & $\mathrm{y}=-0.014 \mathrm{x}$ & 0.925 \\
& -0.218 & & +3.179 & \\
18 & $\mathrm{y}=0.048 \mathrm{x}$ & 0.926 & $\mathrm{y}=-0.015+$ & 0.913 \\
& -0.206 & & 3.183 & \\
\hline
\end{tabular}

Gambar 3 dan Gambar 4 dibawah ini berturutturut ditampilkan plot isoterm Langmuir dan Freundlich pada waktu kontak 7 jam.

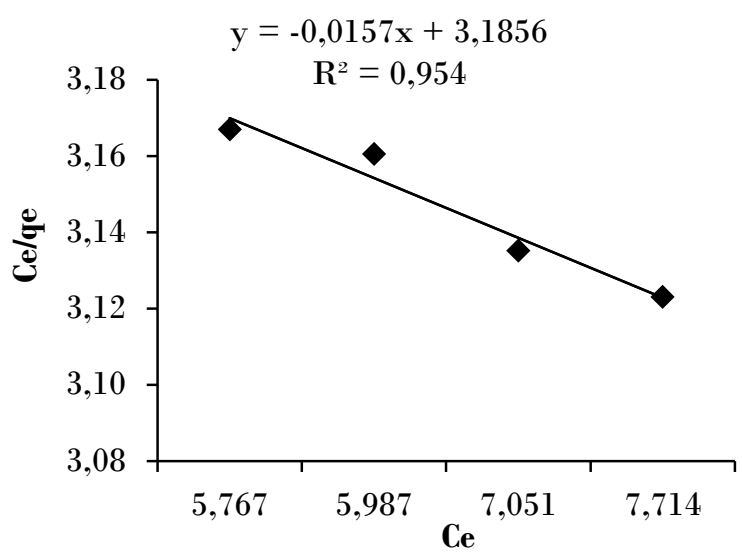

Gambar 3. Plot isoterm Langmuir desorpsi arang aktif terhadap amonia pada waktu kontak 7 jam

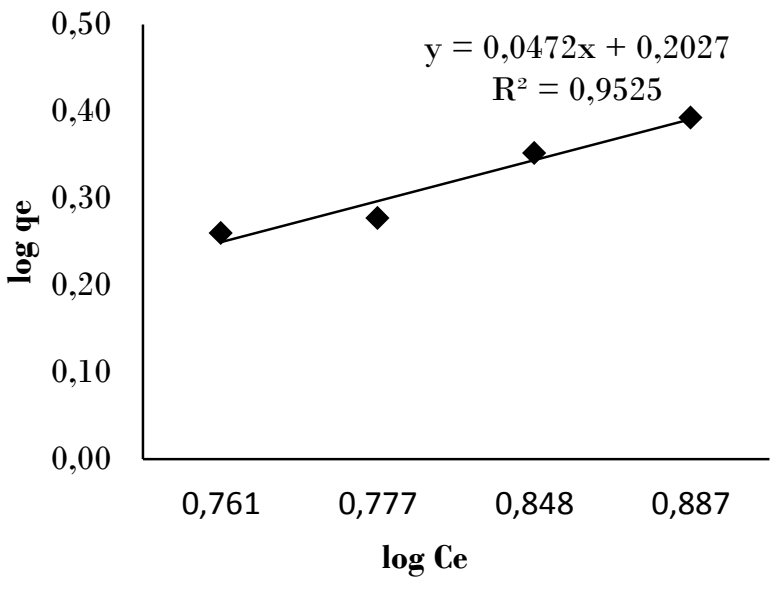

Gambar 4. Plot isoterm Freundlich desorpsi arang aktif terhadap amonia pada waktu kontak 7 jam

Terlihat bahwa harga koefisien relasi $\mathrm{R}^{2}$ untuk model kesetimbangan Langmuir adalah 0.954 dan untuk model kesetimbangan Freunlich adalah 0.952. Antara kedua model kesetimbangan memiliki nilai selisih yang relatif kecil. Sehingga dapat disimpulkan bahwa proses desorpsi arang aktif cangkang sawit terhadap amonia pada percobaan ini memenuhi model kesetimbangan Langmuir $\mathrm{R}^{2}=$ 0.954 dan Freundlich $\mathrm{R}^{2}=0.952$.

\section{Penentuan kapasitas maksimum}

Penentuan kapasitas maksimum dilakukan berdasarkan nilai koefisien relasi $\left(\mathrm{R}^{2}\right)$ terbesar, sehingga dapat mewakili peristiwa yang terjadi pada proses desorpsi. Pada percobaan ini, model kesetimbangan Langmuir memiliki nilai $\mathrm{R}^{2}$ terbesar, sehingga dari hasil linearisasi persamaan tersebut dapat ditentukan kapasitas maksimum desorpsi. Persamaan yang digunakan adalah persamaan Langmuir pada waktu kontak 7 jam yaitu:

$$
y=-0.015 x+3.185
$$

Tabel 2 menunjukkan beberapa parameter hasil perhitungan dari persamaan isoterm Langmuir, dapat dilihat bahwa kapasitas maksimum desorpsi arang aktif cangkang sawit terhadap amonia adalah $66.67 \mathrm{mg} / \mathrm{gram} \mathrm{Q}_{0}$.

Tabel 2. Parameter kesetimbangan Langmuir

\begin{tabular}{cc}
\hline Parameter & Langmuir \\
\hline $\mathrm{R}^{2}$ & 0.954 \\
$\mathrm{Q}_{0}$ & 66.67 \\
$\mathrm{~b}$ & 0.0047 \\
\hline
\end{tabular}




\section{KESIMPULAN}

1. Penambahan dosis arang aktif berpengaruh dalam proses desorpsi arang aktif terhadap amonia. Konsentrasi amonia meningkat seiring dengan semakin meningkatnya massa arang arang aktif yang ditambahkan.

2. Waktu kontak optimum untuk mencapai kesetimbangan pada waktu 7 jam dengan persentase amonia yang terdesorpsi berkisar antara $94-96 \%$.

3. Proses desorpsi amonia dari arang aktif cangkang sawit pada percobaan ini memenuhi model kesetimbangan langmuir $\mathrm{R}^{2}=0.954$ dan model kesetingmbangan Freundlich $\mathrm{R}^{2}=0.952$

4. Model kesetimbangan yang mewakili percobaan ini adalah model Langmuir dengan persaman y $=-0.015 \mathrm{x}+3.185$, dan kapasitas maksimum desorpsi amonia oleh arang aktif adalah 66,67 $\mathrm{mg} / \mathrm{gram}$.

5. Untuk penelitian lebih lanjut, sebaiknya perlu dikaji pengaruh ukuran arang aktif terhadap proses desorpsi arang aktif.

\section{UCAPAN TERIMA KASIH}

Penulis menyampaikan terima kasih yang sebesar-besarnya kepada pihak SMTI Makassar, FTI Universitas Muslim Indonesia atas bantuannya dalam menyelesaikan penelitian ini.

\section{DAFTAR PUSTAKA}

Adha S. D., Danar P dan Rachmat T. T. 2015. Pengaruh Konsentrasi Larutan $\mathrm{HNO}_{3}$ dan Waktu Kontak Terhadap Desorpsi Kadmium (II) yang Terikat pada Biomassa Azzolla microphylla-Sitrat. Fakultas MIPA. Universitas Brawijaya. Malang. Kimia Student Jurnal, 1(1), (36-64).

Aditya K., Yusnimar, dan Zultiniar. 2016. Penentuan Model Isoterm Adsorpsi Ion $\mathrm{Cu}($ II) pada Karbon Aktif Tempurung Kelapa. Laboratorium Teknik Produksi, Fakultas Teknik, Universitas Riau. Pekanbaru. Jom FTeknik, 3(2)

Allwar, Winarsi R., Fitriyani N., Merdekawati K. 2015. Characterization and Application of Actived Carbon from Oil Palm Shell Prepared By Physical Activation and Nitric Acid for the Removal of Phenol and 2-Chlorophenol. Department of Chemistry, Faculty of
Mathematics and Science, Islamic University of Indonesia, Yogyakarta. International Journal of Science and Research(IJSR). ISSN: 2319-7064.

Boopathy R., Karthikeyan S., Mandal A. B., Sekaran G. 2007. Adsorption of ammonium ion by coconut shell-activated carbon from aqueous selution: kinetic, isotherm, and thermodynamic studies. Environ Sci Pollut Res. DOI 10.1007/s11356-012-0911-3

Estiaty, L. M. 2013. Kesetimbangan dan Kinetika Adsorpsi Ion $\mathrm{Cu}^{2+}$ pada Zeolit-H. Riset Geologi dan Pertambangan, 22(2), 127-141. ISSN 0125-9849 e ISSN 23456638.

Irmanto dan Suyata, 2009. Penurunan Kadar Amonia, Nitrat dan Nitrit Limbah Cair Industri Tahu Menggunakan Arang Aktif dari Ampas Kopi. Molekul, 4(2): 105-114.

Freundlich, H.M. 1906. Over the Adsorption in Solution. Journal of Physical Chemistry.57, 385-470.

Langmuir, Irving. 1918. The Adsorption of Gases on Plane Surface of Glass, Mica and Platinum. Journal of the American Chemical Society. 40 (9),1361-1402. doi:10.1021/ja $02242 \mathrm{a} 004$

Mulyono, P dan Wibisono. 2007. Kinetika Adsorpsi Amoniak dalam Air dengan Karbon Aktif. Jurusan Teknik Kimia, Fakultas Teknik, Universitas Gajah Mada. Media Teknik, No.2. ISSN: 0216-3012.

Murti, R. S., Purwanti, C. M., Suyatini. 2013. Adsorpsi Amonia dari Limbah Cair Industri Penyamakan Kulit Menggunakan Abu Terbang Bagas. Majalah Kulit, Karet, dan Plastik. Balai Besar Kulit, Karet, dan Plastik, Yogyakarta.

Panneerselvam, p., Bala, V.S.S., Thiruvengadaraci, K.V., Nandagopal, J., Palanichamy, M. \& Sivanesan, S. 2009. The removal of copper ions from aqueous solution using phosphoric acid modified $\beta$-zeolites. Indian journal of Science and Technology, 2(2): 63-66.

Setyoningrum, T. M., Setiawan, A., \& Pamungkas, G. 2018. Pembuatan Karbon Aktif dari Hasil Pirolisis Ban Bekas. Eksergi, 15(2), 54. https://doi.org/10.31315/e.v15i2.2387 
Smisek M, Cerny S. 1970. Active Carbon, Manufacture, Properties and Application. New York: Elxevier

Syafrianda Irpan., Yenie Elvi., Daud Syarfi. 2017. Pengaruh Waktu Kontak dan Laju Pengadukan Terhadap Adsorpsi Zat Warna pada Air Gambut Menggunakan Adsorben Limbah Biosolid Land Application Industri Minyak Kelapa Sawit. Jom FTEKNIK, 4(2)

Wankasi, D., Horsfall, M. Jnr and Spiff, A. I. 2005. Desorption of $\mathrm{Pb} 2+$ and $\mathrm{Cu} 2+$ from Nipa Palm(Nypa Fruticans Wurmb) Biomass. Department of Pure and Applied Chemistry, Faculty of Science, Niger Delta University. African Jurnal of Biotechnology, 4(9), 923927. ISSN: 1684-5315

Zawani, Z., Luqman, C.A., Choong, T. 2008. Equilibrium, Kinetics and Thermodynamics Studies: Adsorption of remazol Black 5 on PKS_AC, Europian Journal of Scientific Research, 37(1) 67-83.

Zheng, H., Han, L., Ma, H., Zheng, Y., Zhang, H., Liu, D., and Liang, S. 2008. Adsorption Characteristics of Ammonium ion by zeolite 13X. Journal of Hazardous Materials. 158(23):577-584. 